Nova Southeastern University

9-1-2012

\title{
Small-Scale Mapping of Indeterminate Arborescent Acroporid Coral (Acropora cervicornis) Patches
}

Brian K. Walker

Nova Southeastern University, walkerb@nova.edu

E. A. Larson

Nova Southeastern University

Alison L. Moulding

Nova Southeastern University, moulding@nova.edu

David S. Gilliam

Nova Southeastern University, gilliam@nova.edu

Find out more information about Nova Southeastern University and the Halmos College of Natural Sciences and Oceanography.

Follow this and additional works at: https://nsuworks.nova.edu/occ_facarticles

Part of the Marine Biology Commons, and the Oceanography and Atmospheric Sciences and Meteorology Commons

\section{NSUWorks Citation}

Brian K. Walker, E. A. Larson, Alison L. Moulding, and David S. Gilliam. 2012. Small-Scale Mapping of Indeterminate Arborescent Acroporid Coral (Acropora cervicornis) Patches .Coral Reefs, (3) : 885 -894. https://nsuworks.nova.edu/occ_facarticles/131.

This Article is brought to you for free and open access by the Department of Marine and Environmental Sciences at NSUWorks. It has been accepted for inclusion in Marine \& Environmental Sciences Faculty Articles by an authorized administrator of NSUWorks. For more information, please contact nsuworks@nova.edu. 


\title{
Small-scale mapping of indeterminate arborescent acroporid coral (Acropora cervicornis) patches.
}

\author{
B. K. Walker, E. A. Larson, A. L. Moulding, D. S. Gilliam \\ Nova Southeastern University Oceanographic Center, National Coral Reef Institute \\ 8000 North Ocean Drive, Dania Beach, Florida 33004 \\ Email: walkerb@nova.edu; Voice: 001-954-262-3675; Fax: 001-954-262-4027
}

Keywords: Acropora cervicornis, patch, mapping, spatial analysis, movement, Florida

The final publication is available at www.springerlink.com. DOI 10.1007/s00338-012-0910-3

Citation: Walker BK, Larson EA, Moulding AL, Gilliam DS (2012) Small-scale mapping of indeterminate arborescent acroporid coral (Acropora cervicornis) patches. Coral Reefs 31: 885-894.

\begin{abstract}
Western Atlantic populations of the staghorn coral Acropora cervicornis have drastically declined over the past few decades. Hence, interest in its ecology and spatial extent has increased. Acroporid corals with indeterminate arborescent growth like A. cervicornis primarily reproduce asexually by fragmentation which can lead to extensive monotypic patches. Since fragmentation is a major component in indeterminate acroporid reproduction, these patches may expand or move over time. Periodic perimeter mapping facilitates comparison of patch areas to determine movement or expansion. A repeatable, lowcost method using a differential GPS carried by a snorkeler was employed to map the perimeter of $A$. cervicornis patches in southeast Florida. Perimeters were mapped over a three-year period. Patch boundaries were dynamic, expanding in one or more directions. Patch areas increased by up to 7.5 times their original size and moved up to $51 \mathrm{~m}$. Results were corroborated by spatial cluster analyses of in situ live coral cover measurements. Getis-Ord Gi* statistic and Anselin Local Moran's I spatial cluster analyses of live coral cover within an array of in situ monitoring plots indicated that significant high cover clusters moved in the direction of mapped patch perimeter expansion. Expansion was coupled by more than 50\% decreases in total live cover. Information gained herein shows that A. cervicornis patches are spatially and temporally dynamic, having implications to long-term permanent transect monitoring studies and framework development. Results may be applicable to other shallow water indeterminate arborescent acroporid coral species.
\end{abstract}

\section{Introduction}

Presently, acroporid species in the Western Atlantic and Caribbean are drastically reduced from recent historical populations (Bruckner 2002; Pandolfi 2002; Acropora Biological Review Team 2005; Miller et al. 2008). The recent decline of Caribbean acroporids, starting in the late 1970s, was largely caused by synergistic effects of disease outbreaks (Gladfelter 1982; Aronson and Precht 2001; Miller et al. 2002), bleaching, hurricanes (Knowlton et al. 1981; Woodley et al. 1981), and, in some cases, cold water events (Davis 1982; Jaap and Sargent 1994). With significantly fewer A. cervicornis in the Western Atlantic and Caribbean from past population densities, there is increasing interest in the ecology and spatial extent of this species (Bruckner 2002). 
Acropora cervicornis is classified as an indeterminate arborescent branching coral (Wallace 1999). Although it can reproduce sexually (Vargas-Ángel and Thomas 2002; Vargas-Ángel et al. 2006), it primarily reproduces asexually through fragmentation (Gilmore and Hall 1976; Highsmith 1982; Neigel and Avise 1983; Williams and Miller 2006). Fragments may subsequently re-attach nearby, establishing cloned colonies, which can lead to extensive areas (Tunnicliffe 1981), sometimes referred to as thickets or patches. Since fragmentation is a major component in indeterminate acroporid reproduction (Gilmore and Hall 1976; Tunnicliffe 1981; Neigel and Avise 1983; Williams and Miller 2006), these patches may expand or move in the direction of causal forces (e.g., dominant wave energy). This may occur seasonally or over longer time periods.

World-wide, surprisingly limited published information exists on the spatial dimensions of acroprid patches. Mapping the perimeter of patches through time facilitates temporal comparisons of geometric parameters (e.g., area, perimeter, geometric center) to determine expansion and movement. Mapping acroporid populations can be accomplished on larger scales $(100 \mathrm{~s} \mathrm{~km})$ by remote sensing techniques (e.g., satellite image analysis) (Purkis et al. 2006; Collier and Humber 2007), but these techniques are relatively expensive and may not be effective at smaller scales $(10 \mathrm{~s} \mathrm{~m})$ due to pixel mixing, albedo effects, and image registration precision. Mapping populations at smaller scales can be accomplished in a variety of ways including side scan sonar (Collier and Humber 2007), pole-mounted video systems on boats (Lidz et al. 2008), mosaics of underwater camera footage (Gleason et al. 2007), and handheld GPS units towed by diver or snorkeler (Devine et al. 2005; Lirman et al. 2010). However, all but the last method require expensive and sometimes propriety equipment or extensive technological research and development.

This study focuses on small-scale mapping of A. cervicornis patches to investigate movement. Although drastic A. cervicornis population decline has occurred in the Caribbean and Western Atlantic, it remains a locally abundant species in several areas (Bruckner 2002; Purkis et al. 2006; Lirman et al. 2010), including numerous patches in southeast Florida (Vargas-Ángel et al. 2003). Here we present a repeatable, low-cost method using a hand-held Wide Area Augmentation System (WAAS) enabled differential global positioning system (DGPS) carried by a snorkeler to map the perimeter of $A$. cervicornis patches in southeast Florida at a small scale. Patch perimeters are measured and compared in a Geographic Information System (GIS) from over a three-year period. Observations are then compared to statistical spatial cluster analyses of in situ live coral cover estimates.

\section{Methods}

Two A. cervicornis patches in southeast Florida, colloquially named BCA and Scooter, (Thickets 1 and 4 respectively in Vargas-Ángel et al. 2006; and "Dave" and "Oakland I" in Vargas-Ángel et al. 2003) were selected for mapping and monitoring (Fig. 1). The patches are areas of semi-continuous A. cervicornis coverage, containing large thickets $\left(>100 \mathrm{~m}^{2}\right)$, small thickets $\left(<100 \mathrm{~m}^{2}\right)$, individual colonies, and small fragments, within close proximity to one another $(<4 \mathrm{~m})$. The perimeter of each patch was mapped by a snorkeler carrying a WAAS-enabled Garmin 76CSx DGPS ( $<3 \mathrm{~m} 95 \%$ typical accuracy) in a clear waterproof bag. Assessments were performed on patches in 3-6 m depth during good sea conditions $(<$ $0.5 \mathrm{~m}$ wave height) with a minimum of $10 \mathrm{~m}$ visibility. A typical assessment entailed the boat dropping the snorkeler in the water approximately $20 \mathrm{~m}$ outside of the patch. The snorkeler swam to the edge and marked GPS waypoints directly over live A. cervicornis colonies along the edge while swimming in one direction, keeping the patch on the same side from the start. The patch perimeter was defined by live colonies greater than $0.5 \mathrm{~m}$ in diameter separated by less than $4 \mathrm{~m}$ from the previous colony. The survey was complete once the snorkeler overlapped the starting point. No prior knowledge of previous surveys was used during the assessment other than the general patch location. 
GPS waypoints were exported into an ArcView Geographic Information System (GIS) using the Minnesota's Department of Natural Resources DNR Garmin program v.5.04. A polygon shapefile was then created by connecting all the waypoints in the order in which they were taken. Planar surface area and perimeter distance were calculated for statistical comparisons between assessments. Polygon centroids (the geometric center) were then determined for each assessment. Distance and heading between centroids was calculated using Tools for Graphics and Shapes Extension (Jenness 2010).

After the initial mapping assessment, each area was gridded in GIS to fit approximately 32 grid nodes in and around the edges of each patch. The coordinates of each grid node defined in situ monitoring plots which were permanently marked for repeated surveying. The initial patch dimensions determined the grid spacing and array. BCA was a rectangular array of 32 plots at $30 \mathrm{~m}$ spacing, and Scooter was a square array of 31 plots at $23 \mathrm{~m}$ spacing.

Each plot was marked with a central pin, and at the time of the surveys, four $3.5 \mathrm{~m}$ lines were laid around the pin in both north-south and east-west directions to define a $7 \mathrm{~m}$ diameter circular area divided into four quadrants. Percent live A. cervicornis cover was estimated by a diver for each plot by visually assessing the percentage of planar area of live coral using the quadrant divisions as measurement guides while hovering 3-4 $\mathrm{m}$ above. The area of live coral per plot was then calculated by the following formula:

$$
\mathrm{A}=38.48 \mathrm{~m}^{2}(\% \text { live coral })
$$

BCA was first mapped on 14 September 2007. It was first assessed on 30 June 2008. BCA was then subsequently mapped and assessed on the four following dates: 13 February 2009; 19 June 2009; 8 July 2010; and 23 February 2011. Scooter was mapped and assessed on the six following dates: 8 February 2008; 13 February 2009; 22 July 2009; 16 February 2010; 8 July 2010; and 22 February 2011. The assessments conducted in February were considered winter samples, and the June and July assessments were summer samples. Mapping and in situ data were collected the same day.

Spatial statistics tools in ArcGIS 10 were used to analyze spatial clustering of live coral cover plot data. First, a spatial cluster analysis using a Getis-Ord Gi* statistic was performed to identify spatial clusters of high and low values by calculating a z-score and p-value of live coral cover for each plot (Getis and Ord 1992). The z-scores and p-values determine whether spatial clustering of high and low live coral cover values was different than those expected in a random distribution. High z-scores $(>2)$ and low p-values $(<0.05)$ indicated a spatial clustering of high live coral cover, and low negative $\mathrm{z}$-scores $(<-2)$ and low $\mathrm{p}$ values indicated clustering of low live coral cover. Z-scores near zero indicated no apparent spatial clustering.

Next, an Anselin Local Moran's I spatial cluster and outlier analysis was performed. This analysis identified clusters of plots with similar live coral cover values like the Gi* statistic, but it also identified statistical spatial outliers (high live coral cover surrounded by low cover or vice versa) (Anselin 1995). A local Moran's I, a z-score, a p-value, and a code representing the cluster type was calculated for each plot. The $\mathrm{z}$-scores and p-values determined the statistical significance of the computed index values. A positive I indicated that a plot was part of a cluster, and a negative I indicated that it was an outlier. However, this required the p-value to be small enough for the cluster or outlier to be considered statistically significant. The output was displayed to distinguish between a statistically significant ( 0.05 level) cluster of high live coral cover (HH), cluster of low live coral cover (LL), and outliers which either had a high cover plot surrounded by low cover (HL) or a low cover plot surrounded by high cover (LH).

Finally, an Inverse Distance Weighted (IDW) interpolation model was created using the in situ live coral cover data for each patch to better visualize the temporal changes in cover. IDW works on the basic principle of spatial autocorrelation that assumes things closer together are more similar than those farther 
apart. It uses the surrounding data to predict values between data points, weighing closer points more heavily. IDW surfaces were created for each site for each assessment period.

\section{Results}

\section{BCA}

Perimeter mapping revealed that BCA increased in areal extent by $3095.3 \mathrm{~m}^{2}$, from $7330.5 \mathrm{~m}^{2}$ to 10425.8 $\mathrm{m}^{2}$ (Table 1 and Fig. 2). This was a $42 \%$ increase in area during the 1259 day period between the initial and last assessments, equating to a mean expansion rate of $2.5 \mathrm{~m}^{2}$ day ${ }^{-1}$. However, the rate of increase was not linear (Fig. 3). During the first 2 years, between Fall 2007 and Winter 2009, BCA decreased in size by $266.4 \mathrm{~m}^{2}$. Then it increased by $385 \mathrm{~m}^{2}$ in six months, followed by a $676.6 \mathrm{~m}^{2}$ increase the next year. The largest increase occurred between Summer 2010 and Winter 2011 when it increased by $2064.3 \mathrm{~m}^{2}$, which was nearly a $25 \%$ increase in area in six months.

Polygon centroid analyses, the geographic center of an individual polygon, indicated that BCA expanded westward, mostly between the last assessment periods (Fig. 2). In the first two years, between Fall 2007 and Winter 2009, the patch center hardly moved $\left(0.5 \mathrm{~m}\right.$ at $\left.126^{\circ}\right)$ (Table 1$)$. From Winter 2009 to Summer 2009 , it moved $4 \mathrm{~m}$ west $\left(285^{\circ}\right)$, followed by $1.9 \mathrm{~m}$ westward movement the next year. Then in six months, between Summer 2010 and Winter 2011, the center moved $11.7 \mathrm{~m}$ west $\left(281^{\circ}\right)$. In total, the polygon centroid moved west approximately $17.6 \mathrm{~m}$ in a 3.5 year period.

Although patch expansion was evident, total live coral cover area of all plots combined from Summer 2008 through Winter 2011 decreased $92 \mathrm{~m}^{2}$ (Fig. 4). Most of this loss occurred between Summer 2008 and Winter 2009 where live cover decreased by $77 \mathrm{~m}^{2}$, a $44 \%$ decline in six months. Live cover showed temporal periodicity at BCA where cover increased between winter and summer sampling periods and decreased between summer/fall and winter. However, the net live cover declined each year compared to the previous year's same period.

Change in live cover was obvious in the Inverse Distance Weighted (IDW) surface models (Fig. 5). Summer 2008 showed high amounts of live cover within most of the perimeter boundary, including one plot with 70\%. Subsequent sample periods spatially illustrate the reduction of live cover showing both the overall decrease by the reduction of red and orange areas through time and the temporal periodicity with the summer models having more red and orange than the winter ones.

Spatial cluster analyses of live cover supported both the IDW models and the perimeter mapping results. Both the Getis-Ord Gi* statistic and the Anselin Local Moran's I analyses showed statistically significant clustering of high values inside the patch perimeter. The Gi* statistic showed no clustering and low cluster values around the outside of the patch; however they were not significant. High value clusters exhibited westward movement during the study period supporting the western extension found in perimeter mapping. The four center plots and one to the east showed significant clustering between Summer 2008 and Winter 2010, all periods with little measured perimeter change (Fig. 3). In Summer 2010 the cluster lessened to four plots and shifted west one plot, and in Winter 2011 the cluster added another western plot, the same period of the mapped westward perimeter expansion.

\section{Scooter}

Perimeter mapping showed that Scooter increased over 7.5 times its original mapped area in 3 years from $2944.7 \mathrm{~m}^{2}$ to $22566.0 \mathrm{~m}^{2}$. Areal extent increased by $19621.2 \mathrm{~m}^{2}$ during the 1112 day period between the initial and last assessments, equating to a mean expansion rate of $17.6 \mathrm{~m}^{2}$ day $^{-1}$ (Table 2 and Fig. 6). Unlike BCA, the patch expansion rate was more linear with only one substantial rate decrease between 
Summer 2009 and Winter 2010 (Fig. 3). Like BCA, the most notable expansion happened in the last six months between Summer 2010 and Winter 2011, where the patch expanded $6973.4 \mathrm{~m}^{2}$, growing nearly $45 \%$ larger than the previously mapped size.

The patch perimeter overlay illustrates both north and south expansion through time. However, the north was the predominant direction, and thus the centroid data reflected a northern expansion (Fig. 6). Polygon centroid analyses showed that Scooter expanded northward $(51.1 \mathrm{~m})$ between Winter 2008 and Summer 2010, then slightly westward ( $8 \mathrm{~m}$ ) between Summer 2010 and Winter 2011 (Table 2).

Like BCA, patch expansion at Scooter was coupled with live coral cover declines. Total live cover area of all plots combined decreased by $140 \mathrm{~m}^{2}$ between Fall 2009 and Winter 2011 (Fig. 4). Also like BCA, live cover declined dramatically between Summer 2008 and Winter 2009 where live cover dropped $59 \mathrm{~m}^{2}$, a $23 \%$ reduction. Unlike BCA, live cover at Scooter recovered the next summer/fall (2009) to similar levels of the previous year before declining precipitously. Live cover between Fall of 2009 and Winter 2011 consistently declined from $259 \mathrm{~m}^{2}$ to $119 \mathrm{~m}^{2}$ respectively. This $140 \mathrm{~m}^{2}$ loss equates to a $54 \%$ reduction in live coral cover in a little over a year.

Changes in live cover were obvious in the Inverse Distance Weighted (IDW) surface models at Scooter as well (Fig. 7). Summer 2008 showed the highest amount of live cover within most of the perimeter boundary, including two plots with $60 \%$. Subsequent sample periods spatially showed decreasing live cover by the reduction of red and orange areas and the increase of greens and blues through time. The IDW models also illustrated the movement of highest live cover from the southwest in Summer 2008 and 2009 to the north in Winter 2010 and 2011.

As with BCA, spatial cluster analyses supported the IDW models and the perimeter mapping results. Both the Gi* statistic and the Moran's I showed statistically significant clustering of high values inside the patch perimeter. The Gi* showed no clustering and low cluster values around the outside of the patch, yet only two plots were significant (<-2.0); plot 25 in Summer 2008 and plot 31 in Summer 2009. High value clusters exhibited northward movement during the study period, supporting the mapping results. The core two to three high cover plot clusters remained located in the southwest portion of the patch between Summer 2008 and Winter 2010, yet the northeastern plots showed signs of clustering evident by the higher Gi* z-scores (Fig. 7). Summer 2010 exhibited little signs of significant clustering with only one southern plot having a significant Gi* z-score and none in the Anselin Local Moran's I. Then, in Winter 2011 five northern plots formed a significant cluster of relatively high values during the same period the mapping indicated a substantial northern expansion.

\section{Discussion}

In 2001, Vargas-Ángel et al. (2003) described the staghorn patches in southeast Florida as flourishing and an "interesting counterpoint to the declining and disease-stricken A. cervicornis populations reported in the Florida Keys and wider Caribbean." They reported estimated areas at BCA of 3,300 $\mathrm{m}^{2}$ and Scooter of $1,900 \mathrm{~m}^{2}$. Although not directly comparable, their estimations indicated much smaller patch sizes than those reported here. Patch size in 2011 was over 3 times larger at BCA and nearly 12 times larger at Scooter than 2001 estimates; thus it appears that these patches have been expanding since 2001.

Expansion was recognized to happen in two ways. First, small colonies appeared near the periphery of the existing patch either by fragmentation (more likely) or sexual recruitment (less likely). If these small colonies remained in place and grew larger, they met the size criteria $(>0.5 \mathrm{~m})$ to be included in subsequent surveys. Second, gaps were filled between the patch and larger colonies that were greater than $4 \mathrm{~m}$ away. These spaces were either filled by fragmentation and reattachment of nearby colonies, or by colony growth. As colonies grew, they lessened the distance to the patch edge and were included. It 
seemed that Scooter primarily expanded by the first method whereas the second was more apparent in the western expansion of BCA.

Concurrent with expansion, our data showed a 52\% and 54\% reduction of live coral cover at BCA and Scooter, respectively, during the study period. Although our plots were designed to determine temporal changes in significant spatial clustering of live coral cover and not to estimate the total coral cover within the patch, this loss of cover trend was consistent with two concurrent monitoring efforts at BCA, though differing methods preclude direct comparisons. Percent cover in permanent transects videotaped at BCA showed a 16\% decline in cover between 2008 and 2009 (Gilliam 2010), matching the steepest decline in our data during the same period. The same transects also detected more drastic declines where mean coral cover dropped from $39 \%$ to $25 \%$ between 2005 and 2006. Similarly, a second monitoring effort using still photographs along a permanent transect measured a $22 \%$ decline in percent cover at BCA (site FTL-6 in report) between 2004 and 2008 (Gilliam et al. 2010).

The paradox of patch expansion coupled with declining live coral cover is intriguing. A. cervicornis primarily reproduces asexually by fragmentation (Gilmore and Hall 1976; Tunnicliffe 1981; Neigel and Avise 1983; Williams and Miller 2006). Live colonies that are dislodged to new locations would change the amount of live cover at both the original location and the new location. The original colony would show a decrease in live cover unless it is able to recover from the fragmentation and replace the lost growth. If the nearby fragmented colonies are able to attach and survive, they will grow, increasing live cover at the new location. Thus, has coral cover truly declined yielding a net loss of live tissue, or has it simply spread out over a larger area? Detailed studies on fragmented colonies and fate-tracking fragments are required to address this question. Our study was designed to estimate in situ live coral cover in evenly spaced plots in and around the patch for cluster analysis to corroborate the patch boundary mapping results. Changes in live cover were evident, including temporal periodicity and a long-term decline, but the fate of coral outside of the plots was not tracked and remains unknown.

The dynamic nature of these A. cervicornis patches may be inhibiting framework development. Fragmentation of taller colonies may be exhibited by a flattening and spreading of the patch through time and impede the accumulation of framework in a given location. Geologic studies show that $A$. cervicornis historically existed in southeast Florida throughout the Holocene and contributed to significant reef accretion (Lighty et al. 1978). In 2001, estimated patch ages were 20 years (Vargas-Ángel et al. 2003) equating to an approximate age of 30 years today. With local extant A. cervicornis extension rates of up to $10 \mathrm{~cm} \mathrm{yr}^{-1}$ (Shinn 1976), nearly $300 \mathrm{~cm}$ of framework could be expected today if not for growth-limiting and erosional factors. Although height was not measured in our study, no obvious changes in colony height were evident, and there was no previous evidence of reef framework building in the extant patches (Vargas-Ángel et al. 2003). The lack of framework accretion may give the false appearance that the patches are newer additions to the local community.

The plasticity of patch boundaries and potential long-term movement has implications on stationary permanent monitoring efforts. Patch boundaries are not static and, at least in southeast Florida, may be too dynamic for long-term ( $>10 \mathrm{yrs}$ ) permanent transect monitoring. Over time, the patch may move beyond the footprint of the permanent transects. Other survey designs may be better suited for long-term monitoring of dynamic staghorn coral patches (Williams et al. 2006). Plot methods used for this study and similar to those developed for A. palmata monitoring by Williams et al. (2006) are a potentially better alternative. They can be positioned in a grid within and around a patch to monitor both spatial and temporal changes of numerous metrics, providing a robust analysis of the patch ecology. Furthermore, new plots can be added around the periphery in the direction of patch movement.

Considering the importance and abundance of acroporid corals to coral reef ecosystems worldwide, there is surprisingly little published data on mapping the perimeter and area of patches. This may be due to the 
complexities of consistently measuring patches in situ. Over the past decade, the advances in geographic information systems and global positioning systems now enable cost-efficient, accurate mapping and tracking of patch movements. Differential global positioning system (DGPS) mapping is a proven method in terrestrial mapping (Clegg et al. 2006; Dauwalter et al. 2006) and wildlife telemetry (Hulbert and French 2001). DGPS mapping is as effective as traditional methods (e.g., measuring tape) in measuring length, width, and areas of features and provides much faster data collection (Dauwalter et al. 2006). It is more difficult to utilize in marine studies because satellite signals do not penetrate water. Marine DGPS mapping requires either a surface receiver or a tethered antenna. In shallow, clear water $(<7 \mathrm{~m})$, a DGPS carried by a snorkeler is a good low-cost $(<\$ 400$ USD) option.

Spatial scale must be considered in DGPS mapping because the percent error increases nonlinearly with decreasing spatial scale (Webster and Cardina 1997; Dauwalter et al. 2006). Errors are too large in features less than $15 \mathrm{~m}^{2}$ relative to their size, thus using this method for mapping very small areas is not recommended. These errors are negligible at scales over $100 \mathrm{~m}^{2}$ (Dauwalter et al. 2006). Since the patches in this study were on the scale of 1,000 to $10,000 \mathrm{~m}^{2}$, the percent error introduced by the DGPS is thought to be very low $(<1 \%)$. Although accuracy and precision were not tested here, the mapping results illustrated consistent measurement in areas of little observed change indicating that DGPS-introduced error was low.

Our data show that A. cervicornis patches can be spatially and temporally dynamic, which has implications on framework development and long-term permanent transect monitoring studies. Future monitoring will capture the ultimate fate of the Scooter and BCA and whether the current trend of decreasing cover will continue; however declining cover at permanent monitoring stations may not be as foreboding for more mobile coral species like A. cervicornis. Information gained herein may apply to other arborescent acroporids with indeterminate growth worldwide.

\section{Acknowledgements}

This manuscript is a result of research partially funded by the National Oceanic and Atmospheric Administration Coastal Ocean Program under award NA03NOS4260046 to Nova Southeastern University for the National Coral Reef Institute. Thanks to Allison Brownlee, Stephanie Bush, Paola Espitia-Hecht, Daniel Fahy, Mauricio Lopez Padierna, Jennifer Mellein, Zachary Ostroff, Adam St. Gelais, and Charles Walton for their data-collecting assistance. This is NCRI contribution 139.

\section{Literature Cited}

Acropora Biological Review Team (2005) Atlantic Acropora status review document. National Marine Fisheries Service, Southeast Regional Office, St. Petersburg, FL, p 152

Anselin L (1995) Local Indicators of Spatial Association-LISA. Geogr Anal 27:93-115

Bruckner A (ed) (2002) Proceedings of the Caribbean Acropora workshop: Potential application of the U.S. Endangered Species Act as a conservation strategy. NOAA Technical Memorandum NMFSOPR-24, Silver Spring, MD, p199

Clegg P, Bruciatelli L, Domingos F, Jones RR, De Donatis M, Wilson RW (2006) Digital geological mapping with tablet PC and PDA: A comparison. Comput Geosci 32:1682-1698

Collier JS, Humber SR (2007) Time-lapse side-scan sonar imaging of bleached coral reefs: A case study from the Seychelles. Remote Sens Environ 108:339-356

Dauwalter D, Fisher W, Belt K (2006) Mapping stream habitats with a global positioning system: Accuracy, precision, and comparison with traditional methods. Environ Manage 37:271-280

Davis GE (1982) A century of natural change in coral distribution at the Dry Tortugas: A comparison of reef maps from 1881 and 1976. Bull Mar Sci 32:608-623 
Devine B, Rogers C, Loomis C (2005) Mapping marine populations: Using surface water GPS for spatial analysis. Proc Gulf Caribb Fish Inst 56:411-420

Getis A, Ord JK (1992) The analysis of spatial association by use of distance statistics. Geogr Anal 24:189-206

Gilliam D (2010) Southeast Florida Coral Reef evaluation and monitoring project 2009: Year 7 Final Report. Florida DEP report \#RM085, Miami Beach, FL, p 42

Gilliam D, Dodge R, Spieler R, Jordan L, Goergen E (2010) Marine biological monitoring in Broward County, Florida: Year 9 Annual Report. Prepared for the BC Board of County Commissioners, BC Natural Resources Planning and Management Division, Fort Lauderdale, FL, p105

Gilmore MD, Hall BR (1976) Life-history, growth habits, and constructional roles of Acropora cervicornis in patch reef environment. J Sediment Petrol 46:519-522

Gladfelter WB (1982) White-Band disease in Acropora palmata: Implications for the structure and growth of shallow reefs. Bull Mar Sci 32:639-643

Gleason ACR, Lirman D, Williams D, Gracias NR, Gintert BE, Madjidi H, Pamela Reid R, Chris Boynton G, Negahdaripour S, Miller M, Kramer P (2007) Documenting hurricane impacts on coral reefs using two-dimensional video-mosaic technology. Mar Ecol 28:254-258

Highsmith RC (1982) Reproduction by fragmentation in corals. Mar Ecol Prog Ser 7:207 226

Hulbert IAR, French J (2001) The accuracy of GPS for wildlife telemetry and habitat mapping. J Appl Ecol 38:869-878

Jaap W, Sargent F (1994) The status of the remnant population of Acropora palmata (Lamarck, 1816) at Dry Tortugas National Park, Florida, with a discussion of possible causes of changes since 1881. In: Ginsburg RN (ed) Proceedings of the colloquium on global aspects of coral reefs: health, hazards and history. University of Miami, Miami, FL, pp101-105

Jenness J (2010) Tools for graphics and shapes: Extension for ArcGIS. Jenness Enterprises, Available at: http://www.jennessent.com/arcgis/shapes_graphics.htm

Knowlton N, Lang JC, Christine Rooney M, Clifford P (1981) Evidence for delayed mortality in hurricane-damaged Jamaican staghorn corals. Nature 294:251-252

Lidz BH, Brock JC, Nagle DB (2008) Utility of shallow-water ATRIS images in defining biogeologic processes and self-similarity in skeletal Scleractinia, Florida Reefs. J Coast Res:1320-1338

Lighty RG, MacIntyre IG, Stuckenrath R (1978) Submerged early Holocene barrier reef south-east Florida shelf. Nature 275:59-60

Lirman D, Bowden-kerby A, Schopmeyer S, Huntington B, Thyberg T, Gough M, Gough T, Gough R, Gough Y (2010) A window to the past: documenting the status of one of the last remaining 'megapopulations' of the threatened staghorn coral Acropora cervicornis in the Dominican Republic. Aquat Conserv: Mar Freshw Ecosyst 20:773-781

Miller M, Bourque A, Bohnsack J (2002) An analysis of the loss of acroporid corals at Looe Key, Florida, USA: 1983-2000. Coral Reefs 21:179-182

Miller SL, Chiappone M, Rutten LM, Swanson DW (2008) Population status of Acropora corals in the Florida Keys. Proc 11th Int Coral Reef Symp:775-779

Neigel JE, Avise JC (1983) Clonal diversity and population structure in a reef-building coral, Acropora cervicornis: Self-recognition analysis and demographic interpretation. Evolution 37:437-453

Pandolfi JM (2002) Coral community dynamics at multiple scales. Coral Reefs 21:13-23

Precht WF, Aronson RB (2004) Climate flickers and range shifts of reef corals. Front Ecol Environ 2:307-314

Purkis SJ, Myint SW, Riegl BM (2006) Enhanced detection of the coral Acropora cervicornis from satellite imagery using a textural operator. Remote Sens Environ 101:82-94

Shinn E (1976) Coral reef recovery in Florida and the Persian Gulf. Environ Geol 1:241-254

Tunnicliffe V (1981) Breakage and propagation of the stony coral Acropora cervicornis. Proc Natl Acad Sci USA 78:2427-2431

Vargas-Ángel B, Thomas J (2002) Sexual reproduction of Acropora cervicornis in nearshore waters off Fort Lauderdale, Florida, USA. Coral Reefs 21:25-26 
Vargas-Ángel B, Thomas JD, Hoke SM (2003) High-latitude Acropora cervicornis thickets off Fort Lauderdale, Florida, USA. Coral Reefs 22:465-473

Vargas-Ángel B, Colley S, Hoke S, Thomas J (2006) The reproductive seasonality and gametogenic cycle of Acropora cervicornis off Broward County, Florida, USA. Coral Reefs 25:110-122

Wallace C (1999) Staghorn corals of the world - A revision of the genus Acropora. CSIRO Publishing, Melbourne

Webster T, Cardina J (1997) Accuracy of global positioning system (GPS) for weed mapping. Weed Technol 11:782-786

Williams D, Miller M (2006) Morphology offers no clues to asexual vs. sexual origin of small Acropora cervicornis (Scleractinia: Acroporidae) colonies. Rev Biol Trop 54:145-151

Williams DE, Miller MW, Kramer KL (2006) Demographic Monitoring Protocols for Threatened Caribbean Acropora spp. Corals. NOAA Technical Memorandum NMFS-SEFSC-543, Miami, FL, 91

Woodley JD, Chornesky EA, Clifford PA, Jackson JBC, Kaufman LS, Knowlton N, Lang JC, Pearson MP, Porter JW, Rooney MC, Rylaarsdam KW, Tunnicliffe VJ, Wahle CM, Wulff JL, Curtis ASG, Dallmeyer MD, Jupp BP, Koehl MAR, Neigel J, Sides EM (1981) Hurricane Allen's impact on Jamaican coral reefs. Science 214:749-755

Table 1. BCA polygon statistics.

\begin{tabular}{|l|l|l|l|l|l|}
\hline Date & Perimeter $(\mathrm{m})$ & Area $\left(\mathrm{m}^{2}\right)$ & Change $\left(\mathrm{m}^{2}\right)$ & $\begin{array}{l}\text { Centroid } \\
\text { Distance }(\mathrm{m})\end{array}$ & $\begin{array}{l}\text { Centroid } \\
\text { Heading }\left({ }^{\circ}\right)\end{array}$ \\
\hline Fall 2007 & 459.5 & 7330.5 & - & - & - \\
\hline Winter 2009 & 411.6 & 7299.9 & -266.4 & 0.5 & 126 \\
\hline Summer 2009 & 494.2 & 7684.9 & 385 & 4.0 & 285 \\
\hline Summer 2010 & 450.0 & 8361.5 & 676.6 & 1.9 & 303 \\
\hline Winter 2011 & 524.6 & 10425.8 & 2064.3 & 11.7 & 281 \\
\hline
\end{tabular}

Table 2. Scooter polygon statistics.

\begin{tabular}{|l|l|l|l|l|l|}
\hline Date & Perimeter $(\mathrm{m})$ & Area $\left(\mathrm{m}^{2}\right)$ & Change $\left(\mathrm{m}^{2}\right)$ & $\begin{array}{l}\text { Centroid } \\
\text { Distance }(\mathrm{m})\end{array}$ & $\begin{array}{l}\text { Centroid } \\
\text { Heading }\left({ }^{\circ}\right)\end{array}$ \\
\hline Winter 2008 & 377.5 & 2944.7 & - & - & - \\
\hline Winter 2009 & 440.9 & 7580.4 & 4635.7 & 16.6 & 355 \\
\hline Summer 2009 & 647.6 & 11027.6 & 3447.2 & 12.7 & 337 \\
\hline Winter 2010 & 774.2 & 11688.5 & 660.9 & 6.9 & 328 \\
\hline Summer 2010 & 764.3 & 15592.6 & 3904.1 & 14.9 & 16 \\
\hline Winter 2011 & 936.5 & 22566.0 & 6973.4 & 8.1 & 259 \\
\hline
\end{tabular}




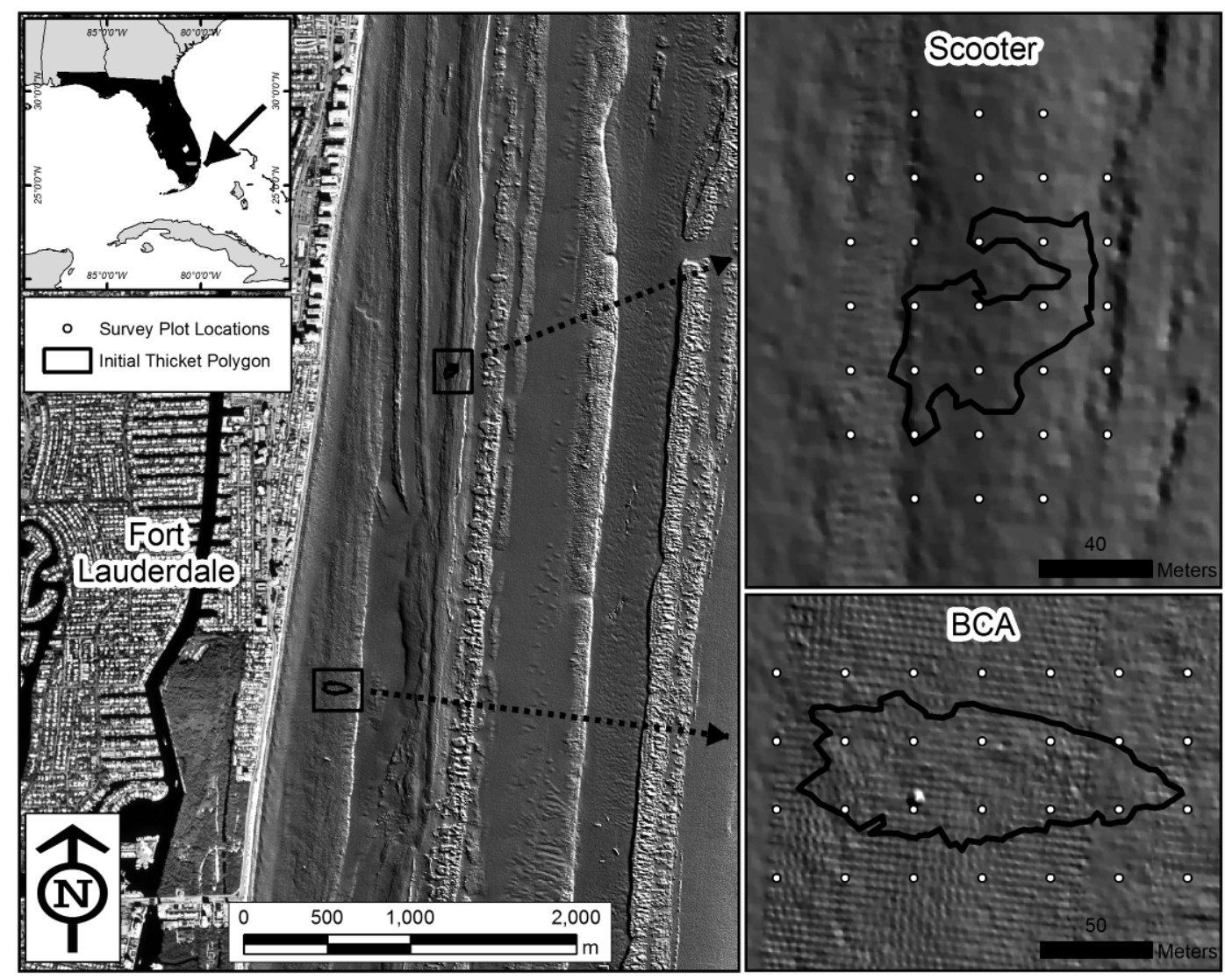

Figure 1. Overview of study area. Outlines show the initial survey perimeters for two Acropora cervicornis patches on the nearshore ridge complex in Fort Lauderdale, Florida. White dots indicate the in situ monitoring plot locations. Grey surface is a high resolution hillshaded bathymetry.

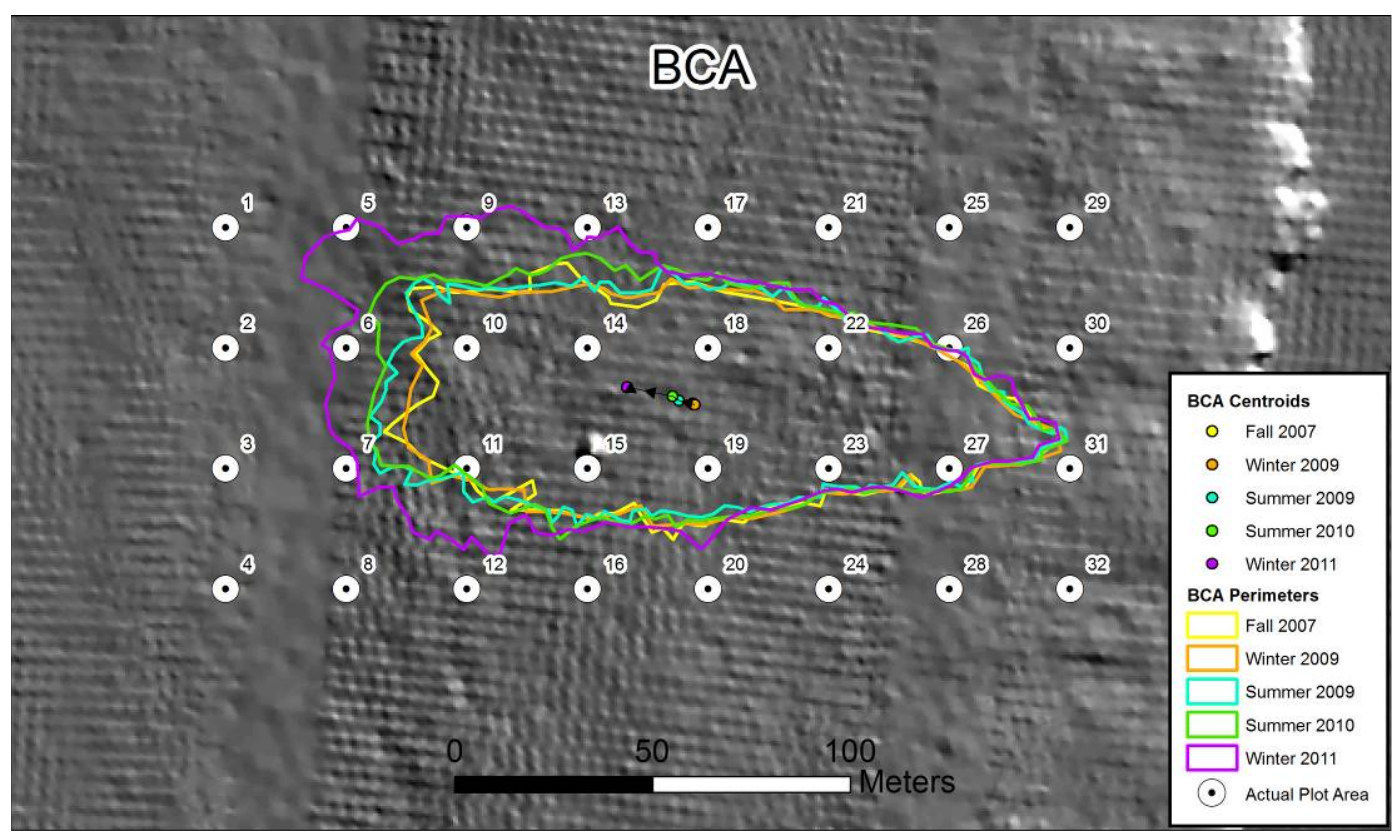

Figure 2. BCA patch perimeters from Fall 2007 through Winter 2011 overlain on high resolution hillshaded bathymetry. The patch has exhibited clear northward and westward expansion. Unlike Scooter, nearly half of BCA has remained very consistent throughout the monitoring, confirming methodological consistency in areas of little change. 


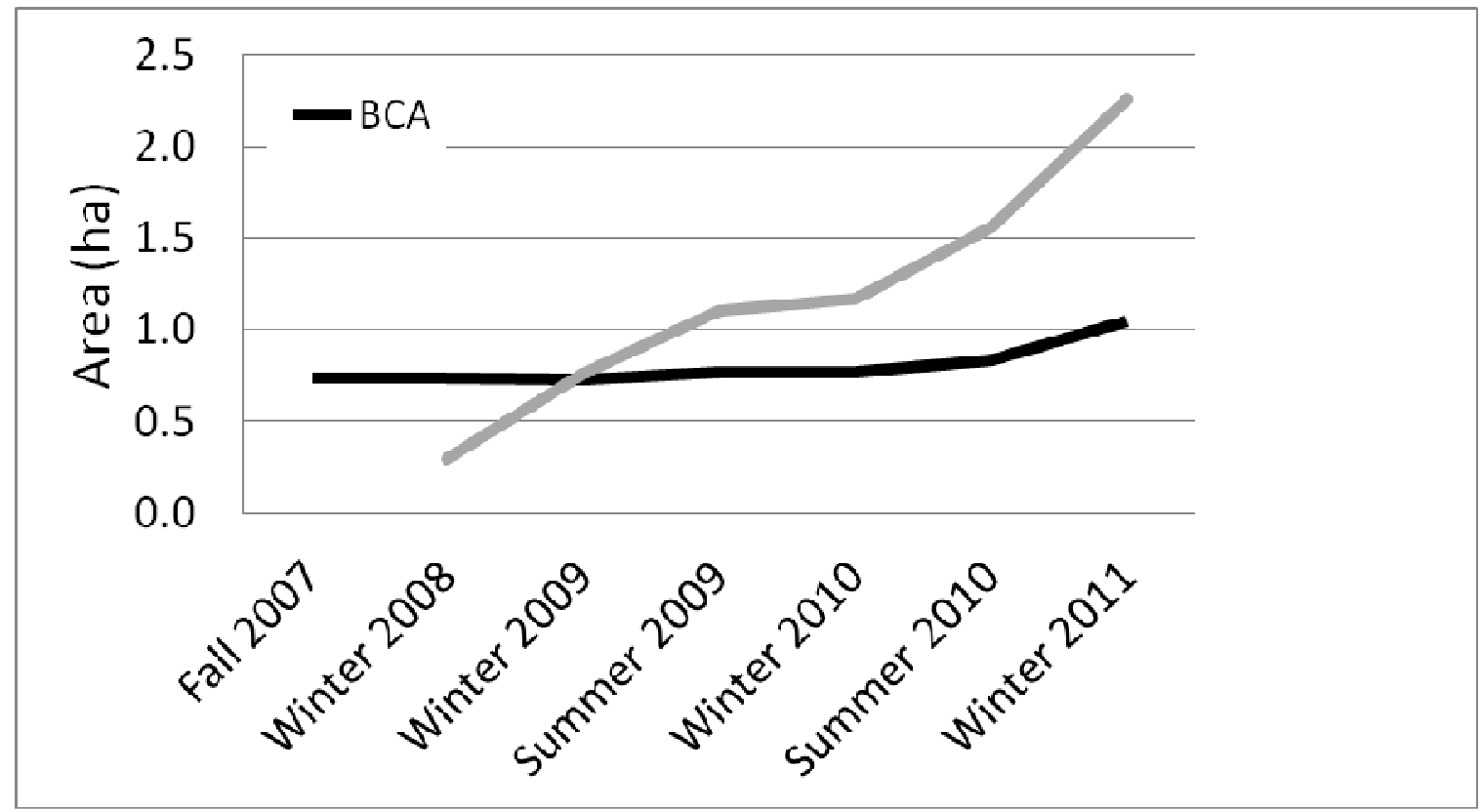

Figure 3. Increase in patch area from Fall 2007 through Winter 2011. Scooter (gray) expanded 2 ha in size while BCA (black) expanded 0.3 ha. 1 hectare $($ ha $)=10,000 \mathrm{~m}^{2}$.

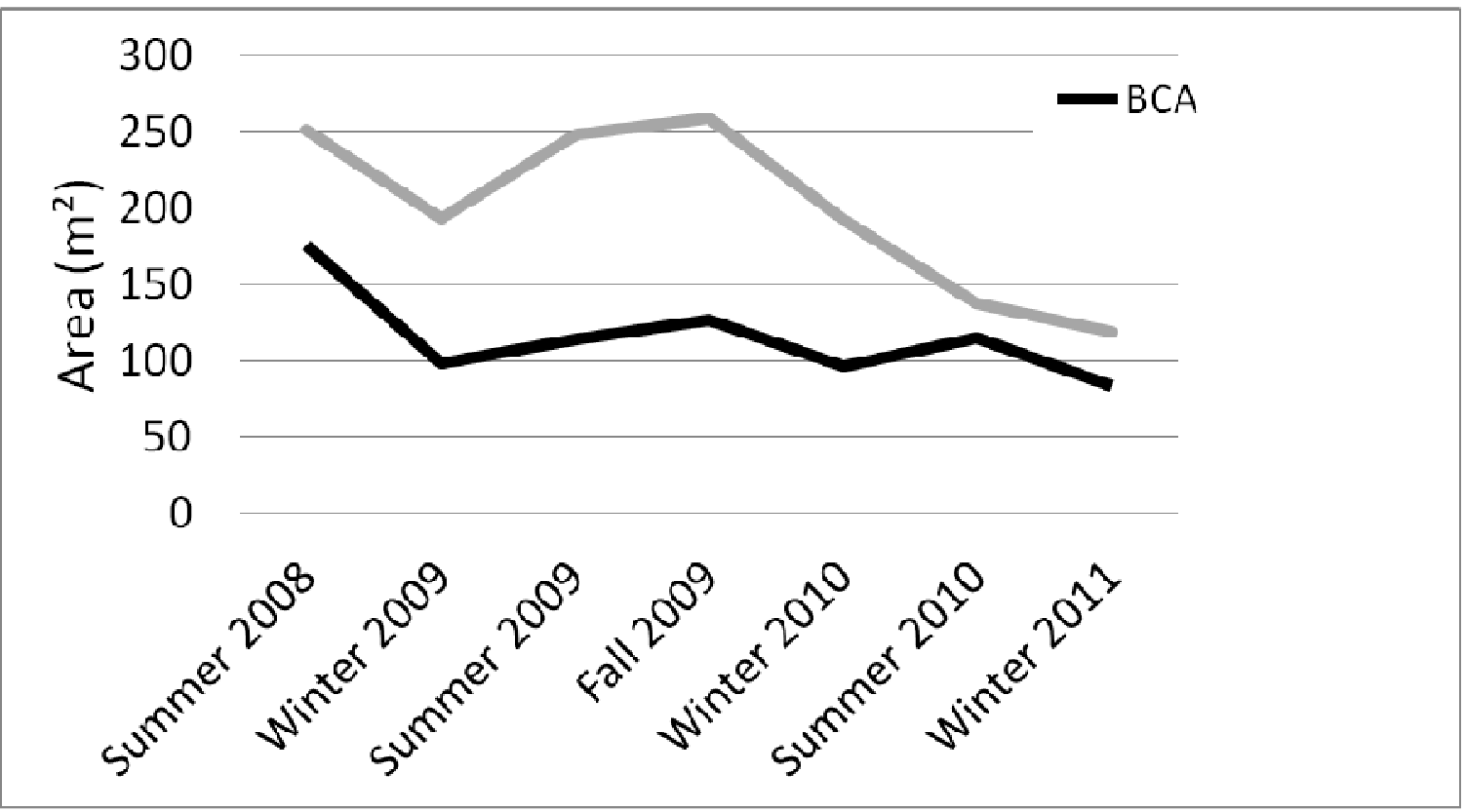

Figure 4. Total live coral cover area of all plots from Summer 2008 through Winter 2011. Scooter (gray) showed temporal periodicity the first year but decreased $140.1 \mathrm{~m}^{2}$ from Fall 2009 to Winter 2011. BCA (black) showed evidence of temporal periodicity on a declining trajectory decreasing $91.97 \mathrm{~m}^{2}$ since Summer 2008. 

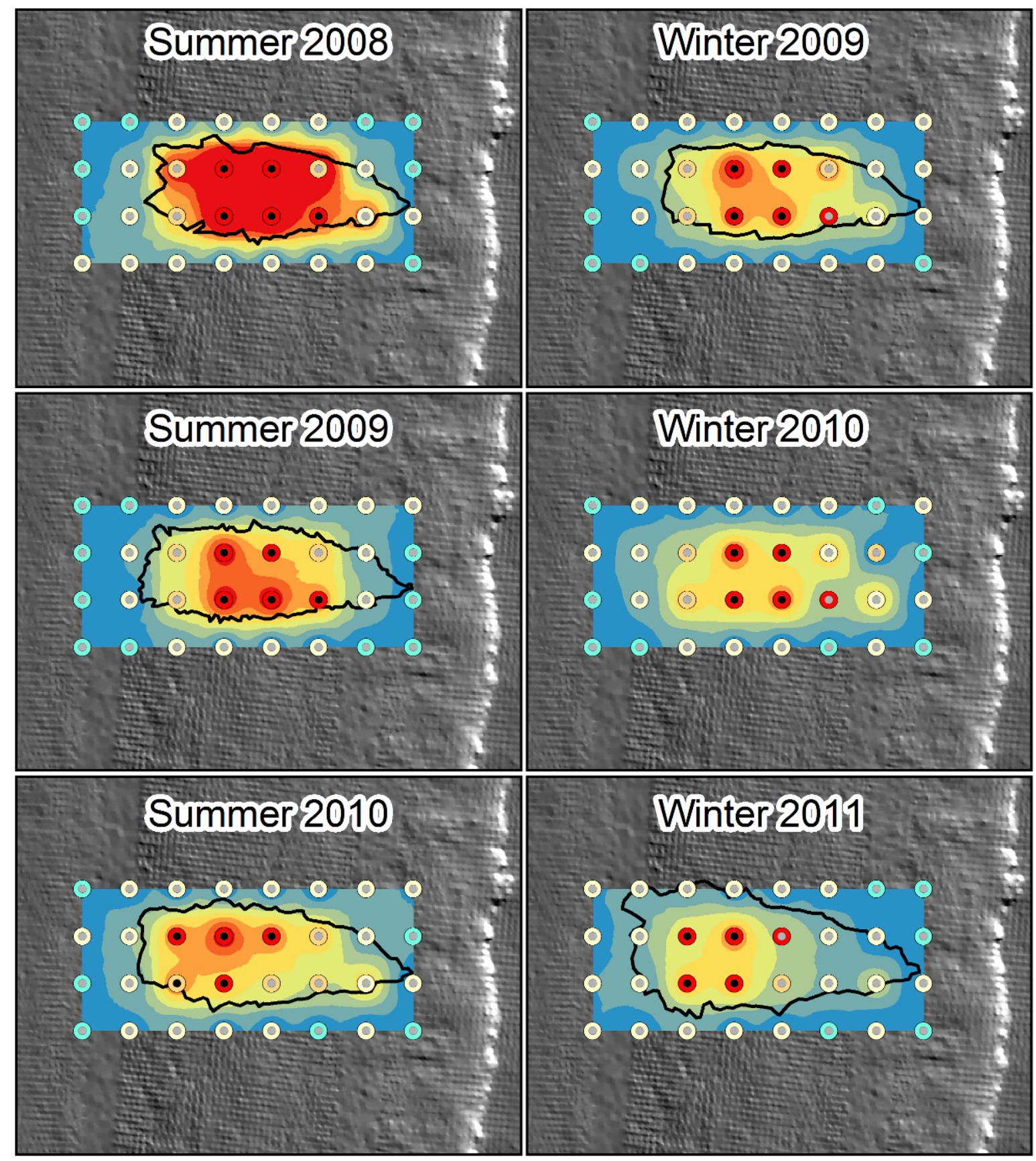

$\begin{array}{lcl}\begin{array}{l}\text { Anselin Local Moran's I } \\ \text { Not Significant }\end{array} & \text { Getis-Ord Gi* Z-S } \\ \text { - HH } & 0 & -2.0 \text { to }-1.0 \\ \text { HL } & 0 & -1.0 \text { to } 1.0 \\ \text { LH } & 0 & 1.0 \text { to } 2.0 \\ & & >2.0\end{array}$

IDW Predicted Cover

Figure 5. BCA plot cluster analysis and inverse distance weighted interpolation illustrating the temporal changes in live coral cover. Live coral cover decreased during the study period and significantly high clusters (black dots) moved west during the monitoring period supporting the westward expansion seen in the perimeter mapping. Grey surface is a high resolution hillshaded bathymetry. 


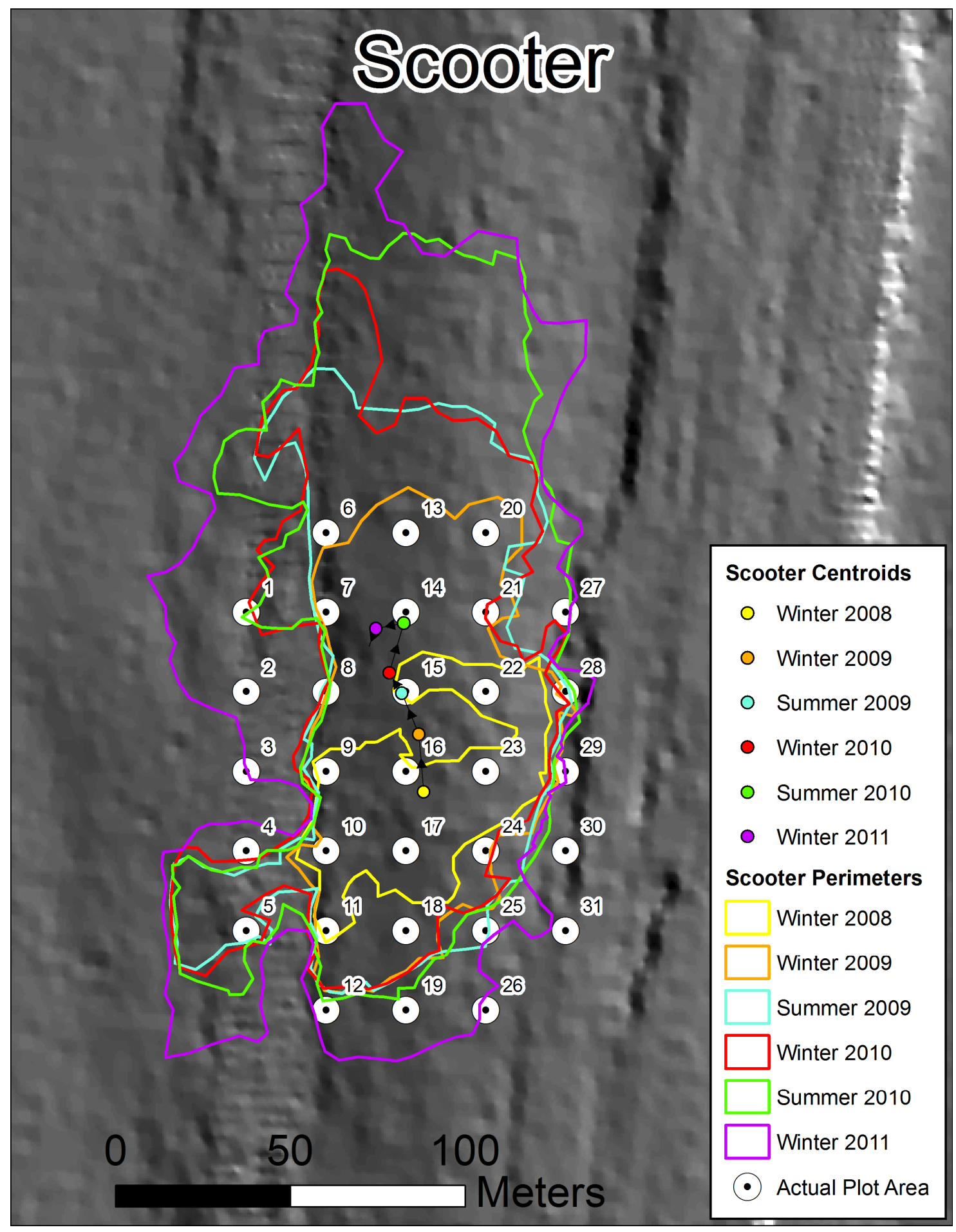

Figure 6. Scooter patch perimeters from Winter 2008 through Winter 2011 overlain on high resolution hillshaded bathymetry. The patch has exhibited clear north-south and west expansion. Very few areas in the 2011 perimeter are close to the initial survey edges. Patch centroid (colored dots) moved approximately $51 \mathrm{~m}$ north-northwest over the three year period. 


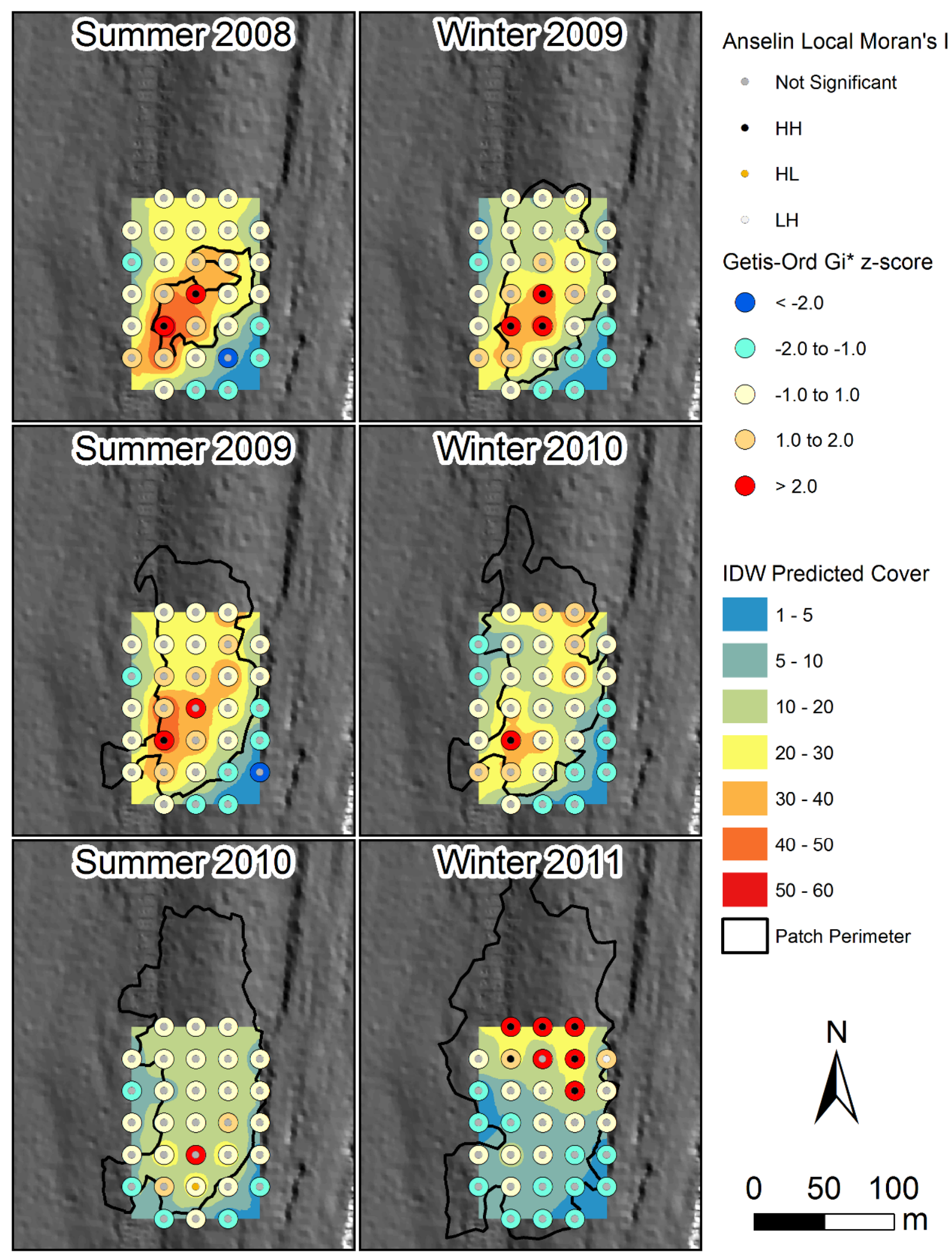

Figure 7. Scooter plot cluster analysis and inverse distance weighted interpolation illustrating the temporal changes in live coral cover. The highest amount of live coral cover moved north during the monitoring period supporting the northward expansion seen in the perimeter mapping. Grey surface is a high resolution hillshaded bathymetry. 